http://jmscr.igmpublication.org/home/ ISSN (e)-2347-176x ISSN (p) 2455-0450

crossref DOI: https://dx.doi.org/10.18535/jmscr/v9i2.17

\title{
Treatment of Intraosseous benign Fibrocollagenous Inflammatory Growth Associated with Nonvital Maxillary right Central Incisor by Surgical Excision, Apicoectomy and Apical Root Repair Using White MTA with 13 Months Follow Up
}

\author{
Authors \\ Dr Prashant Acharya ${ }^{1}$, Dr Neesha Kumari ${ }^{2}$ \\ ${ }^{1}$ Regional Hospital Bilaspur Himachal Pradesh \\ ${ }^{2}$ Prakshroop Dental Clinic, Bilaspur Himachal Pradesh
}

\begin{abstract}
Pulpal disease leads to periapical lesions. Root apices have morphological irregularities in teeth with periapical lesions therefore the periapical pathology persists after many root canal debridement and intracanal medicament follow-ups resulting in the failure of the root canal treatment. Failure of conventional orthograde endodontic treatment for a large non healing periapical lesion can be managed by apical surgery with the success rate being 86-92\%. MTA has wide range of applications in endodontics due to its biocompatibility, potential for hard tissue induction and sealing ability. This case report describes the treatment and 13 months follow-up of the teeth with large periapical lesion using MTA as apical filling material.
\end{abstract}

Keywords: Intraosseous benign fibrocollagenous inflammatory growth, Apicoectomy, Apical root repair, MTA.

\section{Introduction}

Sometimes the conventional root canal treatment fails to produce desired results and the periapical pathology persists after many root canal debridement and intracanal medicament follow-ups. The goal of the obturation is to obtain a fluid-tight seal of the root canal system from its coronal aspect through its apical extent to preserve it from the irritants of microbial invasion. ${ }^{1}$ Root apices have morphological irregularities in teeth with periapical lesions. Therefore, it is more difficult to produce hermetically apical stop with conventional guttapercha obturation techniques ${ }^{2}$ and also the sealer can be resorb with time ${ }^{3}$ resulting in the failure of the root canal treatment. ${ }^{2}$
MTA has proven to have several potential clinical applications due to its superior sealing property, ability to set in the presence of blood ${ }^{4}$, bactericidal effects, and biocompatibility ${ }^{5}$ and new cement formation ${ }^{6}$ with other desired properties of the ideal root canal filling materials including the ability to adhere and seal the root canal system hermetically, non-toxicity and toleration of periradicular tissues, dimensional stability, non resorbability, and resistance to the presence of moisture ${ }^{7}$, making it an ideal bioactive material to initiate bone healing in periapical bone loss due to periapical inflammatory pathosis as the same illustrated in our case. 


\section{Case Report}

A patient presented to the outpatient dental department of a regional hospital with the complaints of severe pain with abscess in relation to maxillary right central incisor with a history of recurrent swelling and pus discharge since 8 months. Intraoral periapical radiograph (IOPA) of the patient was done which showed periapical radiolucency of size $1 \times 0.5 \mathrm{~cm}$ with root resorption of the said tooth. After the failure of conventional root canal with persistent pus discharge and no change in the status of periapical radiolucency, a surgical treatment approach was planned and a trapezoid mucoperiosteal flap raised to access the bony defect, with the help of sharp bony curettes the lesion was exposed. Deeper manipulation and debridement yielded a firm fibrous soft tissue mass $1.5 \times 1.5 \mathrm{~cm}$ extended up to the base of nasal cavity eroding the underlying nasopalatine bones of right maxilla. Apicoectomy of the root apex undergoing resorption followed by debridement of the remaining apical portion was done and repaired using white MTA that was also pushed into the apical third of root canal. Excision biopsy of the lesion revealed nonneoplastic fibrocollagenous growth having dense mixed inflammatory infiltrate comprised of polymorphs, lymphocytes, plasma cells and a few macrophages. After a 6 months follow-up a considerable reduction in periapical radiolucency with good amount of maxillary bone formation of variable radioopacity and discernable bony trabeculle formation was seen in IOPA radiographs at the defect site.

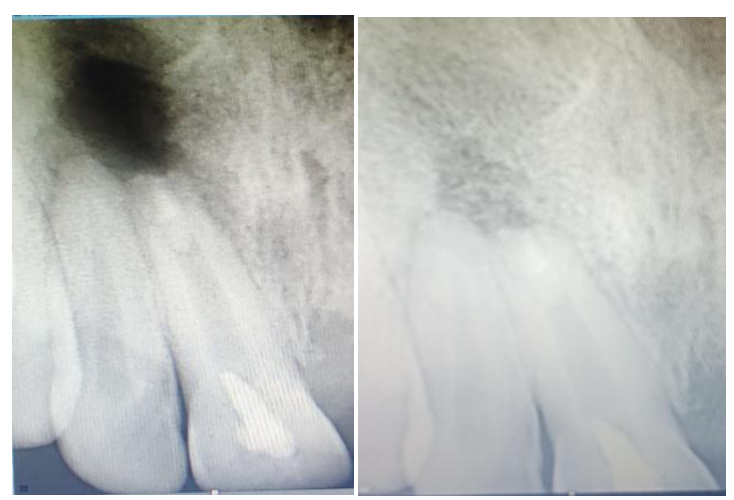

Fig. 1(a) Immediate post-op IOPA (b) 13 months post-op IOPA

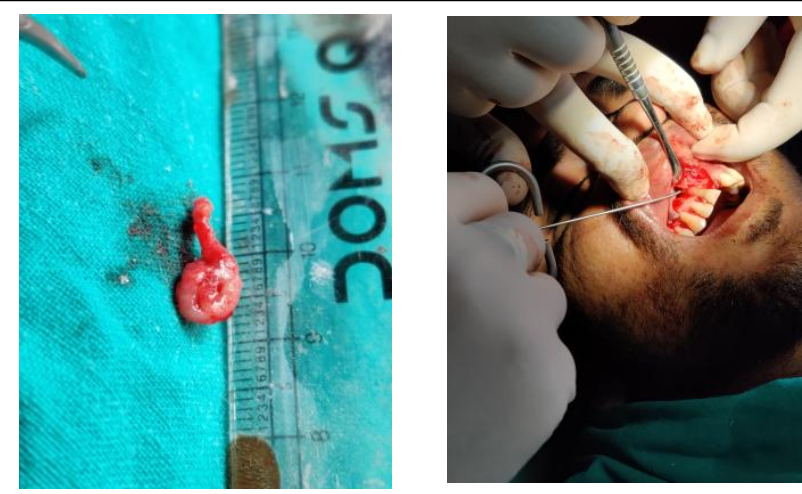

Fig. 2(a) Exised fibrocollagenous growth (b) MTA in-situ

\section{Discussion}

The goal of a periradicular surgery is to gain access to the affected area, evaluate the root circumference and root canal anatomy, and place a biocompatible seal in the form of root end filling that stimulates the regeneration of periapical tissues. The principal modality available to manage failure of conventional orthograde endodontic treatment for a large non healing periapical lesion is apical surgery with the success rate being $86-92 \%{ }^{8}$ Large cyst-like periapical lesions can drastically change the treatment to more complex procedures with nonsurgical approach being one of the options for managing such cases. However, it requires multiple visits for intracanal medicament placement before permanent filling of the root canal space. This may not be suitable for time constrained patients. ${ }^{9}$

Various cements have been used as root end filling materials. The choice of a root end filling material could be governed by handling properties, biocompatibility, apical seal, and long-term clinical success. MTA has been investigated and used as a root end filling material since its introduction. Despite its good physical and biological properties and it being hydrophilic in nature; its use has always remained a challenge because of its technique sensitivity, prolonged setting time, and high cost. The search for an alternative material was with the aim to reduce cost and increase the feasibility for both professionals and patients. ${ }^{10}$ The low cytotoxic potential of MTA explains its wide range of applications in endodontics. ${ }^{11}$ It has been shown that the human osteoblasts were able to attach and proliferate on MTA surfaces, suggesting the suitable 
use of this material adjacent to bone. ${ }^{12}$ In addition, MTA is responsible for induction of hydroxyapatite crystal on its surface on contact with tissue fluids, which makes it a bioactive material. ${ }^{13}$ The material derives its biocompatibility, potential for hard tissue induction and sealing ability from this phenomenon. $^{14}$

Assessment of healing of periapical lesions Repair of periradicular tissues consists of a complex regeneration involving bone, periodontal ligament, and cementum. ${ }^{15}$ The area of mineral loss gradually fills with bone and the radiographic density increases. ${ }^{16}$ If the cortical plate is perforated, healing begins with the regeneration of the external cortical plate and proceeds from the outside of the lesion toward the inside. ${ }^{17}$ Maxillary lesions resolve faster than mandibular lesions due to the presence of a more extensive vascular network in the maxilla, which facilitates resolution. Anterior lesions of both the maxilla and mandible heal at a faster rate than posterior lesions due to the close proximity of the buccal and lingual plates in the anterior segments. ${ }^{18}$ The success-failure criteria laid down by Strindberg is primarily a system designed to detect changes in radiographic appearance. The criteria for success are that: (a) the contours, width, and structure of the periodontal margin are normal; (b) the periodontal contours are widened mainly around the excess filling; and the criteria for failure are: (a) a decrease in the periradicular rarefaction; (b) unchanged periradicular rarefaction; (c) an appearance of new rarefaction or an increase in the initial rarefaction. ${ }^{17}$ Even though the periapical conditions are viewed as a continuous process of healing or developing periodontitis, the system is strictly dichotomous, that is, there is no middle ground between success and failure. ${ }^{16}$ The area measurement assessment method can be used to monitor the healing of periapical lesions. The rate of repair can be calculated by dividing the size differential between the initial and follow-up visits by the number of elapsed months. On the basis of the average healing rate of approximately $3 \mathrm{~mm} 2 / \mathrm{mo}$, a $30 \mathrm{~mm} 2$ lesion will require 10 months for complete resolution. If the lesion becomes larger, remains the same size or demonstrates a below average rate of healing, then surgical intervention must be considered. However, the measurement involves only two dimensions, because it is not possible to evaluate the buccolingual extent. ${ }^{18}$ Another assessment tool is the 'periapical index' (PAI), which provides an ordinal scale of five scores ranging from 'healthy' to 'severe periodontitis with exacerbating features. 19 Of late, an ultrasound with color power Doppler has been demonstrated to be an efficacious monitoring tool in the healing of periapical lesions. ${ }^{20}$

\section{Conclusions}

The use of MTA in the treatment of large periapical lesion is not a routine application; however, our case illustrated that it may be used clinically in the treatment of the teeth with large periapical lesion. We recommend further multicentric researches to evaluate the use of MTA in the periapical root canal lesions of endodontic origin.

\section{References}

1. Schilder H. Filling root canals in three dimensions. Dent Clin North Am 1967;11:723-745

2. Y Tahsin, G Nimet Use of Mineral Trioxide Aggregate in the Treatment of Large Periapical Lesions: Reports of Three Cases. Eur J Dent 2010;4:468-474

3. Peters DD. Two year in vitro solubility evaluation of four guttapercha sealer obturation techniques. J Endod 1986;12: 139-145

4. 4. Torabinejad M, Higa RK, McKendry DJ, Pitt Ford TR. Dye leakage of four root end filling materials: effects of blood contamination. J Endod 1994;20:159-163

5. Torabinejad M, Hong CU, Pitt Ford TR, Kettering JD. Antibacterial effects of some root end filling materials. J Endod 1995;21: 403-406.

6. Yildirim T, Gencoglu N, Firat I, Guzel O, Perk C. Histologic study of furcation perforation treated with MTA or Super EBA in dog's teeth. Oral Surg Oral Med Oral 
Pathol Oral Radiol Endod 2005;100:120124.

7. Dorn SO, Gartner AH. Retrograde filling materials: a retrospective success-failure study of amalgam, EBA, and IRM. J Endod 1990;16:391-393.

8. Girish CS, Ponnappa K, Girish T, Ponappa M. Sealing ability of mineral trioxide aggregate, calcium phosphate and polymethylacrylate bone cements on root ends prepared using Erbium: Yttriumaluminium garnet laser and ultrasonics evaluated by confocal laser scanning microscopy. J Conserv Dent 2013;16:304-8.

9. Fernandes M, de Ataide I. Nonsurgical management of periapical lesions. J Conserv Dent 2010;13:240-5.

10. Septodont Biodentine ${ }^{\mathrm{TM}}$ Active Biosilicate Technology TM scientific file, 2010.

11. M. Torabinejad and N. Chivian, "Clinical applications of mineral trioxide aggregate," Journal of Endodontics, vol. 25,no. 3, pp. 197-205, 1999.

12. E. AL-Rabeah, H. Perinpanayagam, and D. MacFarland, "Human alveolar bone cells interact with ProRoot and tooth-colored MTA," Journal of Endodontics, vol. 32, no. 9, pp. 872-875, 2006.

13. M. G. Gandolfi, P. Taddei, A. Tinti, and C. Prati, "Apatite forming ability (bioactivity) of ProRoot MTA," International Endodontic Journal, vol. 43, no. 10, pp. 917-929, 2010.

14. Pradnya S. Nagmode, Archana B. Satpute, The Effect of Mineral Trioxide Aggregate on the Periapical Tissues after Unintentional Extrusion beyond the Apical Foramen, Hindawi Publishing Corporation Case Reports in Dentistry Volume 2016, Article ID $\quad 3590680, \quad 5 \quad$ pages http://dx.doi.org/10.1155/2016/3590680.

15. Ørstavik D. Radiographic evaluation of apical periodontitis and endodontic treatment results: A computer approach. Int Endod J 1991;41:89-98.
16. Huumonen S, Ørstavik D. Radiological aspects of apical periodontitis. Endod Topics 2002;1:3-25.

17. Strindberg LZ. The dependence of the results of pulp therapy on certain factors. An analytical study based on radiographic and clinical follow-up examinations. Acta Odontol Scand 1956;14:1-175.

18. Murphy WK, Kaugars GE, Collet WK, Dodds RN. Healing of periapical radiolucencies after nonsurgical endodontic therapy. Oral Surg Oral Med Oral Pathol 1991;71:620-4

19. Ørstavik D, Kerekes K, Eriksen HM. The periapical index: A scoring system for radiographic assessment of apical periodontitis. Endod Dent Traumatol 1986;2:20-34.

20. Rajendran N, Sundaresan B. Efficacy of ultrasound and color power Doppler as a monitoring tool in the healing of endodontic periapical lesions. J Endod 2007;33:181-6. 